\title{
Thermal limits for flight activity of field-collected Culicoides in the United Kingdom defined under laboratory conditions
}

\author{
Laura A. Tugwell ${ }^{1}{ }^{*}$, Marion E. England ${ }^{1}$, Simon Gubbins ${ }^{1}$, Christopher J. Sanders ${ }^{1}$, Jessica E. Stokes ${ }^{1}$, \\ Joanne Stoner ${ }^{1}$, Simon P. Graham ${ }^{1,2}$, Alison Blackwell ${ }^{3}$, Karin E. Darpel ${ }^{1}$ and Simon Carpenter ${ }^{1}$
}

\begin{abstract}
Background: Culicoides biting midges (Diptera: Ceratopogonidae) are biological vectors of internationally important arboviruses and inflict biting nuisance on humans, companion animals and livestock. In temperate regions, transmission of arboviruses is limited by temperature thresholds, in both replication and dissemination of arboviruses within the vector and in the flight activity of adult Culicoides. This study aims to determine the cold-temperature thresholds for flight activity of Culicoides from the UK under laboratory conditions.

Methods: Over 18,000 Culicoides adults were collected from the field using $4 \mathrm{~W}$ down-draught miniature ultraviolet Centers for Disease Control traps. Populations of Culicoides were sampled at three different geographical locations within the UK during the summer months and again in the autumn at one geographical location. Activity at constant temperatures was assessed using a bioassay that detected movement of adult Culicoides towards an ultraviolet light source over a 24-h period.

Results: The proportion of active adult Culicoides increased with temperature but cold temperature thresholds for activity varied significantly according to collection season and location. Populations dominated by the subgenus Avaritia collected in South East England had a lower activity threshold temperature in the autumn $\left(4^{\circ} \mathrm{C}\right)$ compared with populations collected in the summer $\left(10^{\circ} \mathrm{C}\right)$. Within the subgenus Avaritia, Culicoides scoticus was significantly more active across all temperatures tested than Culicoides obsoletus within the experimental setup. Populations of Culicoides impunctatus collected in the North East of England were only active once temperatures reached $14^{\circ} \mathrm{C}$. Preliminary data suggested flight activity of the subgenus Avaritia does not differ between populations in South East England and those in the Scottish Borders.

Conclusions: These findings demonstrate seasonal changes in temperature thresholds for flight and across different populations of Culicoides. These data, alongside that defining thresholds for virus replication within Culicoides, provide a primary tool for risk assessment of arbovirus transmission in temperate regions. In addition, the study also provides a comparison with thermal limits derived directly from light-suction trapping data, which is currently used as the main method to define adult Culicoides activity during surveillance.
\end{abstract}

Keywords: Ceratopogonidae, Culicoides, Bluetongue virus, African horse sickness virus, Phototaxis, Thermal limits

*Correspondence: laura.tugwell@pirbright.ac.uk

${ }^{1}$ The Pirbright Institute, Ash Road, Woking GU24 ONF, UK

Full list of author information is available at the end of the article

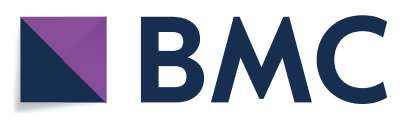

(c) The Author(s) 2021. This article is licensed under a Creative Commons Attribution 4.0 International License, which permits use, sharing, adaptation, distribution and reproduction in any medium or format, as long as you give appropriate credit to the original author(s) and the source, provide a link to the Creative Commons licence, and indicate if changes were made. The images or other third party material in this article are included in the article's Creative Commons licence, unless indicated otherwise in a credit line to the material. If material is not included in the article's Creative Commons licence and your intended use is not permitted by statutory regulation or exceeds the permitted use, you will need to obtain permission directly from the copyright holder. To view a copy of this licence, visit http://creativeco mmons.org/licenses/by/4.0/. The Creative Commons Public Domain Dedication waiver (http://creativecommons.org/publicdomain/ zero/1.0/) applies to the data made available in this article, unless otherwise stated in a credit line to the data. 


\section{Background}

Culicoides biting midges (Diptera: Ceratopogonidae) are biological vectors of a range of internationally important arboviruses of companion animals, livestock and wild mammals, including bluetongue virus (BTV), African horse sickness virus (AHSV) and Schmallenberg virus (SBV) $[1,2]$. In addition, Culicoides transmit Oropouche virus (OROV), which causes a febrile illness in humans, and play a poorly defined role in the transmission of a range of other zoonotic arboviruses [3, 4]. Within northern Europe, both BTV and SBV have a significant impact on livestock production through clinical disease and also ruminant movement controls and trade restrictions imposed to reduce virus spread $[5,6]$. The risk of major shifts in the global distribution of Culicoides-borne arboviruses is currently considered to be high $[7,8]$, as illustrated by the recent unprecedented emergence of AHSV in Thailand [9].

In temperate regions, such as north-western Europe, temperature has a fundamental influence on the transmission and persistence of Culicoides-borne arboviruses [10]. The rate of arbovirus replication and dissemination within a biological vector is usually highly dependent on environmental temperature, as most arthropods are poikilothermic. In the case of Culicoides-BTV interactions, the threshold for infection and replication lies within a range of $11-15^{\circ} \mathrm{C}$ [11]. It is clear, however, that the temperature threshold for Culicoides active flight is below this range and therefore could allow survival of the virus through winter periods when replication does not occur, but when infected adults are able to survive, fly and feed on hosts $[12,13]$. It has also been demonstrated that Culicoides infected with AHSV at $25{ }^{\circ} \mathrm{C}$ and then immediately held at a constant temperature of $10^{\circ} \mathrm{C}$ for 35 days develop full infections following a return to $25^{\circ} \mathrm{C}$ for 3 days [14]. Hence, resumption of temperatures conducive to virus replication could also lead to transmission during transient warmer periods within winter.

Temperature-related thresholds to activity in adult Culicoides can be assessed through direct analysis in the laboratory and through a variety of field-based methods. Direct studies of activity use laboratory-based bioassays based on a phototactic response while they are held at a known temperature. A recent study in the Republic of South Africa (RSA) examined the major afrotropical vector of arboviruses, Culicoides imicola Kieffer, and measured flight response using a white fluorescent light stimulus and horizontal flight over a distance of approximately $15 \mathrm{~cm}$ [15]. An earlier study, based in Japan, examined activity using a dedicated bioassay system based on a requirement for $8 \mathrm{~cm}$ of horizontal flight in response to an ultraviolet light source [16]. In both Culicoides oxystoma Kieffer and Culicoides maculatus (Shiraki), active flight was recorded in $<10 \%$ of individuals at temperatures $<16-17{ }^{\circ} \mathrm{C}$, although a few individuals were recorded as being active even at the minimum temperature of $6{ }^{\circ} \mathrm{C}$. In contrast to the study in RSA, over $80 \%$ of individuals exhibited a phototactic response at temperatures of greater than $25^{\circ} \mathrm{C}$.

Activity of adult Culicoides can also be measured in the field by collection in parallel with measurement of environmental temperature. The most epidemiologically relevant method of assessing thermal limits to activity is to measure adult Culicoides blood-feeding behaviour on a relevant host. A key issue is that these studies are generally carried out at times of peak adult seasonal abundance, where thermal limits to activity are not usually reached, and are also limited by the availability of daylight [17]. As an example, collections of adult Culicoides from sheep made in the UK using a drop-trap design reported all species within the subgenus Avaritia as active across the entire temperature sampling range of $11.8-29.0{ }^{\circ} \mathrm{C}$ between the daylight hours of 18:00 and 21:30 [17]. Truck trapping has also been carried out in the UK using a vehicle driven over a set course with a net mounted on its roof [18]. This samples populations of adult Culicoides actively flying at a set height of approximately $1.5 \mathrm{~m}$ without an attractant. Culicoides of the subgenus Avaritia were collected over a range of $8.6-30.0^{\circ} \mathrm{C}$, with larger catches associated with higher temperatures, although reductions in activity were recorded when the temperature exceeded $21{ }^{\circ} \mathrm{C}$ [18]. Both of these approaches are usually only deployed at single sites on a local scale due to their complex logistics.

Thermal limits to Culicoides adult activity can be loosely inferred from less labour-intensive trapping approaches such as, ultraviolet (UV) light-suction traps. Despite their widespread use in Europe for both research activities and surveillance of Culicoides during arbovirus outbreaks [19-21], data collected from winter periods are limited, making it difficult to examine cold temperature thresholds for activity. In France, adult Culicoides activity was inhibited, as measured by an absence of individuals in trap collections, on nights when the maximum temperature fell below $10{ }^{\circ} \mathrm{C}$ [22], and a similar result was found in Germany where activity was limited to days with a maximum temperature of $\geq 10.8{ }^{\circ} \mathrm{C}$ [23]. A field study in the UK was able to collect adult Culicoides, using UV light-suction traps, in February and March when the maximum temperature for both months was $10.1{ }^{\circ} \mathrm{C}$ [24]. Results from a large dataset of Culicoides collections across Europe indicate that the onset of the vector season can occur at 
mean temperatures as low as $1{ }^{\circ} \mathrm{C}$ in the most northern latitude tested, whereas mean temperatures of $10{ }^{\circ} \mathrm{C}$ are required for Culicoides activity in countries in the southern latitudes [21]. Key variations in experimental methods include the method by which temperature is inferred (e.g. in situ, using national weather stationbased monitoring or remotely sensed data) and the fact that light-suction trap collections are not representative of biting rate on hosts in this region [17].

Surveillance of adult Culicoides flight periods, through the use of light-suction traps, is currently adopted in Europe to determine the time period during which the probability of arbovirus transmission is very low, defined as the seasonal vector-free period (SVFP) [25]. Understanding the temperature threshold for flight activity in Culicoides is also critical in evaluating the risk of transmission following an incursion, in addition to understanding their role in arbovirus overwintering in the UK [12]. The implementation of trap surveillance, if not already in place, is time-consuming resulting in a delay of active surveillance from the point of initial incursion. Applying easily accessible temperature data, however, to evaluate the activity rates of Culicoides populations and thus infer the risk of transmission by active Culicoides could overcome the issues associated with post-incursion surveillance. The aim of this study was therefore to determine a cold temperature threshold for flight activity under experimental conditions for field-caught UK Culicoides species, collected at different seasons and geographical locations.

\section{Methods}

\section{Study sites}

Field collections of adult Culicoides were conducted across five sites in the UK (Fig. 1) at different times of the year (Additional file 1: Table S1). In South East England, three equine holdings (site $1: 51^{\circ} 08^{\prime} 46.5^{\prime \prime} \mathrm{N}, 0^{\circ} 36^{\prime} 51.6^{\prime \prime} \mathrm{W}$; site 2: $51^{\circ} 17^{\prime} 26.2^{\prime \prime} \mathrm{N}, 0^{\circ} 39^{\prime} 09.0^{\prime \prime} \mathrm{W}$; site $3: 51^{\circ} 17^{\prime} 00.3^{\prime \prime} \mathrm{N}$, $\left.0^{\circ} 36^{\prime} 24.6^{\prime \prime} \mathrm{W}\right)$ were used for collections in June-August 2017 (South East England summer cohort; SES) and again for collections in September-October 2017 (South East England autumn cohort; SEA). All three sites were predominately used for grazing, with animal stabling and muck heaps present at each site. In North East England, collections were made from a forest campsite (site 4: $55^{\circ} 14^{\prime} 13.1^{\prime \prime} \mathrm{N}, 2^{\circ} 35^{\prime} 12.1^{\prime \prime} \mathrm{W}$ ) during July 2018 (North East England summer; NES). During the same month, a collection was also made at a mixed farm in the Scottish Borders (site 5: 55 $15^{\prime} 44.5^{\prime \prime} \mathrm{N}, 2^{\circ} 41^{\prime} 16.4^{\prime \prime} \mathrm{W}$ ) (Scottish Borders summer cohort; SBS).

\section{Collection methods}

Insects were collected using down-draught miniature blacklight (UV) Centers for Disease Control (CDC), model 912 traps (John W Hock Co, Gainesville, FL, USA). Each CDC trap uses a $4 \mathrm{~W}$ UV tube and is powered by a $12 \mathrm{~V}$ lead acid sealed battery (Yuasa, Japan). At each site, between four and eight traps were used to catch sufficient Culicoides for the trials and were positioned at least $50 \mathrm{~m}$ apart [26]. Traps were suspended at a height of approximately $1.5 \mathrm{~m}$ above ground. Traps were set up at least $2 \mathrm{~h}$ before sunset and run overnight before collection within $2 \mathrm{~h}$ of sunrise the following day. Insects were collected live into a $340 \mathrm{ml}$ cardboard collection cup containing a cotton pad soaked in $10 \%$ sucrose to provide a sugar source and paper towel cut into long, thin strips to provide shelter from the trap fan downdraft. Cardboard collection cups were secured to the CDC trap using a $\mathrm{CDC}$ sleeve and elastic bands (Additional file 2: Figure S1). The following morning, sleeves from each trap were removed and tied with a clip-lock tie to contain the insects within the collection cup and sleeve.

\section{Flight activity experiments}

Insects collected were transferred and released into a

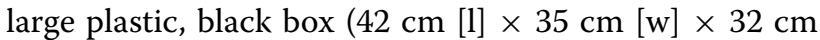
[h]) with a translucent funnel (14 cm long) attached on one side to allow for insects to exit. Clear plastic tubing (6 cm in length) was secured to the translucent funnel to visualise and count approximately 150-250 active, phototactic adult Culicoides exiting the box and entering a 'flight activity pot' (Fig. 2). The flight activity pots were modified $340 \mathrm{ml}$ cardboard collection cups with a small plastic funnel (66 $\mathrm{mm}$ top diameter; $7.4 \mathrm{~cm}$ in length) covered in aluminium foil fitted at the top and a fine mesh covering the bottom of the pot. The total height of the flight activity pot from the base of the cardboard cup to the tip of the funnel was $14 \mathrm{~cm}$. A cotton wool bung within the funnel retained all insects within the flight activity pot until the start of the experiments.

Once eight flight activity pots had been filled, they were numbered at random from one to eight. Pots one to six were placed into a 'test' temperature-controlled incubator (MIR-254 Panasonic, UK) at an initial temperature of $20 \pm 1{ }^{\circ} \mathrm{C}$, while pots seven and eight were placed in a second 'maintenance' incubator also set at $20 \pm 1{ }^{\circ} \mathrm{C}$ as a control for activity of Culicoides in the sample. Both incubators contained a UV light source (4 W blue-blacklight tube; John W Hock Co, Gainesville, FL, USA) suspended within the incubator that acted as an attractant and no other light was provided within the incubators. The test incubator was then set to the desired temperature $\left(2{ }^{\circ} \mathrm{C}-14{ }^{\circ} \mathrm{C}\right)$ and insects were allowed to acclimatise for $2 \mathrm{~h}$. Following the acclimatisation period, the cotton 


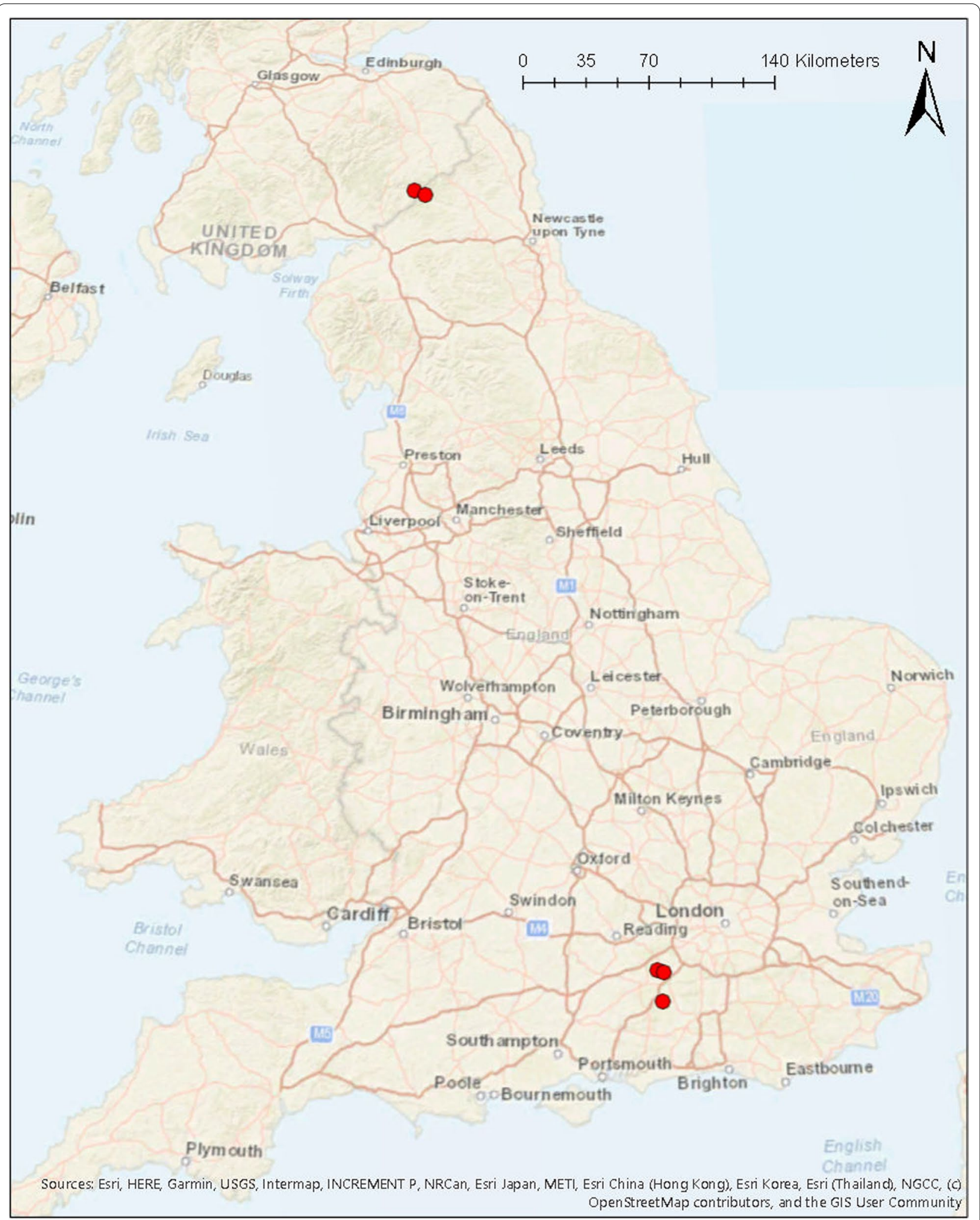

Fig. 1 Map of study sites. A total of five study sites were used: sites 1, 2 and 3 in South East England, site 4 in North East England and site 5 in the Scottish Borders. The red points on the map indicate each study site from where Culicoides were collected 
wool bung at the top of the flight activity pot funnel was removed and a 7.5-cm-diameter pill box (Watkins and Doncaster, UK) with a fine mesh lid was secured on top of the funnel allowing active insects to fly towards the UV light stimulus into the attached pill box (Fig. 2e). All flight activity pots were placed with the mesh lid faced downwards onto a tray to ensure darkness, so that the UV light was the only light source available above the flight activity pots. A small cotton pad soaked in $10 \%$ sucrose was placed underneath each flight activity pot on the tray, rather than within the pot, so that insects could still access the sugar-meal through the fine mesh but were prevented from sticking to the pad.

At regular intervals the collection pill boxes were replaced (0.5-, 1-, 2-, 4-, 6-, 8-, 10- and 24-h intervals) and the collected Culicoides were killed by freezing at $-20^{\circ} \mathrm{C}$ for a minimum of $2 \mathrm{~h}$. All remaining inactive individuals in the flight activity pots were also killed by freezing after $24 \mathrm{~h}$. The percentage of Culicoides flying after $24 \mathrm{~h}$ was determined by calculating the mean cumulative proportion of active Culicoides across the six flight activity pots maintained at each test temperature. In each temperature trial, collections were also made at the same intervals from pots seven and eight, which were maintained at $20 \pm 1{ }^{\circ} \mathrm{C}$ throughout the experiment to ensure the population tested were active without the constraint of cold temperatures. A flow diagram of the full experimental design is provided in Additional file 3: Figure S2. A range of temperatures was tested for the SES, SEA and NES cohorts to cover a range of activity levels that would allow for the determination of a cold temperature threshold. The temperature ranges were ascertained after measuring Culicoides flight activity levels at an initial test temperature of $10{ }^{\circ} \mathrm{C}$. In the SES cohort, five temperatures were tested $\left(6,8,10,12\right.$ and $\left.14{ }^{\circ} \mathrm{C}\right)$ and the SEA cohort a further five temperatures were tested (2, $4,6,8$ and $\left.10{ }^{\circ} \mathrm{C}\right)$. Four temperatures were tested in the $\operatorname{NES}$ cohort $\left(8,10,12\right.$ and $\left.14{ }^{\circ} \mathrm{C}\right)$ and due to time restrictions only one temperature of $12{ }^{\circ} \mathrm{C}$ was tested in the SBS cohort.

\section{Sample identification}

Only individuals that were tested in activity experiments were identified; all surplus insects that remained in the initial black plastic sorting box were not used for experimental study. Culicoides from the activity experiments were sorted morphologically under a dissecting microscope using characteristic wing patterns with the aid of an identification key [27]. Adult Culicoides were grouped into six categories: subgenus Avaritia, Culicoides pulicaris (Linnaeus), Culicoides punctatus (Meigen), Culicoides achrayi Kettle and Lawson, C. impunctatus and
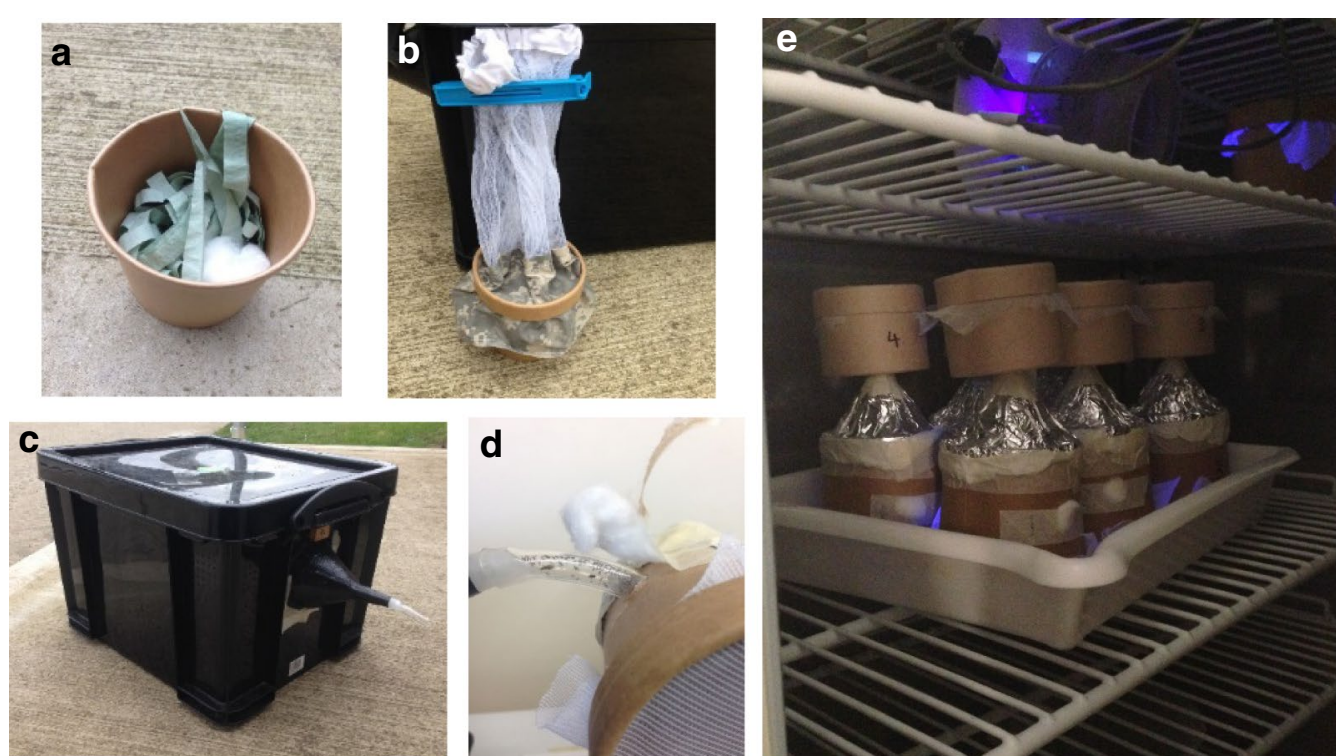

Fig. 2 Photographs of equipment used for collecting and sorting Culicoides collections for the flight activity study. Cardboard collection cup $(340 \mathrm{ml})$ containing a sucrose-soaked cotton wool pad and paper towel strips (a); collection cup and sleeve removed from trap and secured using clip-lock tie (b); black plastic box with funnel at one end with attached clear plastic tubing (c); insects entering flight activity pots from the dark plastic box via the funnel and clear tubing (d); flight activity pots 1-6 were transferred into dark incubators and specifically were placed with the mesh downwards onto a tray to ensure darkness within the flight activity pot. A small sucrose-soaked cotton wool pad was placed underneath and a 7.5-cm-diameter pill box, with a fine mesh lid, was secured on top of the funnel allowing active insects to fly towards the UV light stimulus into the attached pill box $(\mathbf{e})$ 
other Culicoides. Female Culicoides were also identified to physiological state by examination of the abdomen [28] and assigned to one of the following categories: unpigmented, pigmented, gravid and blood-fed.

For both South East England cohorts (SES and SEA), a sub-sample of females within the subgenus Avaritia was identified further to species level $(C$. obsoletus and C. scoticus only) using an adapted multiplex polymerase chain reaction (PCR) method targeting the internal transcribed spacer (ITS) 1-5.8S-ITS2 region [29]. All individuals belonging to the subgenus Avaritia from one flight pot from each temperature trial were chosen at random for molecular analysis and used as a representative sample for each population at each temperature trial. Culicoides were transferred to individual reaction tubes with $200 \mu \mathrm{l}$ of tissue digest solution containing $100 \mathrm{nM}$ Tris$\mathrm{HCl}$ pH8 (Thermo Fisher, UK), $200 \mathrm{mM} \mathrm{NaCl}$ (SigmaAldrich, UK), $0.2 \%(\mathrm{w} / \mathrm{v})$ SDS (Thermo Fisher), $5 \mathrm{mM}$ EDTA (Thermo Fisher), $200 \mu \mathrm{g} / \mathrm{ml}$ proteinase K (Thermo Fisher) and nuclease-free water (Thermo Fisher). Following an overnight incubation in tissue digest solution at $37{ }^{\circ} \mathrm{C}$, individual Culicoides specimens were transferred to tubes containing $70 \%$ ethanol for storage. The Culicoides DNA was then extracted from $100 \mu \mathrm{l}$ of tissue digest solution and eluted into $100 \mu \mathrm{l}$ buffer using the KingFisher Flex automated extraction platform and the MagMAX $^{\mathrm{TM}}$ CORE Nucleic Acid Purification Kit (Thermo Fisher) according to the manufacturer's instructions.

Two microlitres of each sample DNA was added to each well on a PCR plate (Life Technologies, UK), each containing $8 \mu \mathrm{l}$ of mastermix, which consisted of $1 \times$ TaqMan Fast Advanced MasterMix (Thermo Fisher), $0.3 \mu \mathrm{M}$ of each primer [29] and $0.2 \mu \mathrm{M}$ of each probe [29], and diluted to a total reaction volume of $10 \mu \mathrm{l}$ using nuclease-free water (Thermo Fisher). Negative extraction controls consisted of elution from wells which did not contain any Culicoides specimen in the extraction plate and negative PCR controls contained just nuclease-free water. At least three negative controls and at least three positive controls, using DNA extracted from males from the same study morphologically identified as either $C$. obsoletus or C. scoticus, were added to each plate.

The PCR thermal profile used consisted of $2 \mathrm{~min}$ at $50^{\circ} \mathrm{C}$ for activation of uracil-DNA-glycosylases (UDG), an initial denaturation step of $2 \mathrm{~min}$ at $95^{\circ} \mathrm{C}$, followed by 40 cycles of $95^{\circ} \mathrm{C}$ for $3 \mathrm{~s}$ and $60^{\circ} \mathrm{C}$ for $30 \mathrm{~s}$ and was carried out using an Applied Biosystems 7500 Fast instrument (Thermo Fisher). Each plate was analysed using the ViiA7 Real-Time PCR system software (Thermo Fisher). Determination of species for each individual specimen was based on the cycle threshold $\left(C_{t}\right)$ value for each species-specific primer-probe pairing. Negative samples were defined as having a $C_{t} \geq 35$ and positive samples were defined as having a $C_{t} \leq 25$.
Samples with a $C_{t}$ between $>25$ and $<35$ were regarded as undetermined and were repeated. If samples remained undetermined following re-examination, samples were defined as unknown and were removed from analysis.

\section{Statistical modelling}

Generalised linear mixed models (GLMMs) were used to investigate the relationship between temperature and the proportion of Culicoides flying and how this relationship differed amongst cohorts. Specifically, a binomial family GLMM with a logit link function was constructed with the proportion of Culicoides flying as the response variable. Model selection proceeded by stepwise deletion of non-significant $(P>0.05)$ terms (as judged by likelihood ratio tests), starting from a model including temperature $\left({ }^{\circ} \mathrm{C}\right)$, cohort and an interaction between them as fixed effects and pot as a random effect (to allow for betweenpot variation). The models were implemented using the lme4 package [30] in $\mathrm{R}$ (version 3.6.1) [31].

Separate models were constructed for total Culicoides (all Culicoides, unpigmented females and pigmented females), the Avaritia subgenus (all Culicoides, unpigmented females and pigmented females) and C. impunctatus (all Culicoides and pigmented females). Sample sizes were insufficient to examine relationships for: (i) $C$. pulicaris, C. achrayi or other Culicoides or (ii) blood-fed females, gravid females or males for any species/groups. In addition, the SBS cohort was excluded from this analysis as activity was only assessed at a single temperature $\left(12{ }^{\circ} \mathrm{C}\right)$ for this cohort.

Further models were constructed for Culicoides flight activity at $12{ }^{\circ} \mathrm{C}$ to compare activity amongst the SES cohort, NES cohort and SBS cohort. A similar approach to that described above was used, except the model included only cohort as a fixed effect and pot as a random effect. Flight activity in the cohorts was compared using Tukey multiple comparisons.

For the SES and SEA cohorts, there was a sufficient number of Culicoides caught to allow two further analyses. First, to compare flight activity of unpigmented and pigmented females of the Avaritia subgenus a GLMM was constructed including pigmentation state (i.e. unpigmented or pigmented) as a fixed effect as well as two- and three-way interactions between it and the other fixed effects (i.e. temperature and cohort). Model selection was carried out as described above. Second, to compare flight activity of C. obsoletus and C. scoticus, a binomial family generalised linear model (GLM) with a logit link function was constructed. The proportion of Culicoides flying was the response variable and temperature, cohort and species were fixed effects. Model selection proceeded as described above. 


\section{Results}

For both the SES and SEA cohorts, a total of five collections were made to test five temperatures in each cohort. Each collection, made across multiple sites (sites 1 to 3 ), was used to test one temperature at a time. In the SES cohort, a total of 5586 Culicoides were collected across the five collections to test five temperatures $(6,8,10,12$ and $14{ }^{\circ} \mathrm{C}$ ). In the SEA cohort, a total of 5309 Culicoides were collected across the five collections to test five temperatures $\left(2,4,6,8\right.$ and $\left.10^{\circ} \mathrm{C}\right)$. A total of 7228 Culicoides were tested in the NES cohort from a total of four collections from site 4 only to test four temperatures $(8,10,12$, $14{ }^{\circ} \mathrm{C}$ ). One collection was made in the SBS cohort to test one temperature $\left(12{ }^{\circ} \mathrm{C}\right)$ in which 585 Culicoides were tested (Additional file 4: Table S2).

In the South East of England, $>97 \%$ of Culicoides in both the summer (5463 of the 5586 individuals) and autumn (5259 of the 5309 individuals) cohorts belonged to the subgenus Avaritia. In contrast, $>99 \%$ of Culicoides in North East England were identified as C. impunctatus (6611 of the 6643 individuals). There were insufficient numbers collected of other species (C. pulicaris, C. punctatus, C. achrayi and other Culicoides) from all cohorts for further analyses to be conducted on these species. (Additional file 4: Table S2). Collections were also dominated by unpigmented and pigmented female Culicoides and no further analysis was conducted on males, gravid or blood fed females (Additional file 4: Table S2).

In all cohorts where multiple temperatures were tested, the proportion of active Culicoides increased as temperature increased within the range tested (Fig. 3; Additional file 5: Table S3). This relationship was observed for total Culicoides (all adults, unpigmented females and pigmented females), the subgenus Avaritia (all adults, unpigmented females and pigmented females) and C. impunctatus (all adults and pigmented females) in both South East England cohorts (SES and SEA) and the NES cohort (Fig. 3). Moreover, the rate at which Culicoides activity increased with temperature was the same amongst the three cohorts tested, i.e. there was no significant interaction between temperature and cohort (likelihood ratio tests: total Culicoides [all, $\chi^{2}=1.31, \mathrm{df}=2$, $P=0.52$; unpigmented, $X^{2}=0.72, \mathrm{df}=1, P=0.40$; unpigmented, $\left.\chi^{2}=3.70, \mathrm{df}=2, P=0.15\right]$ and subgenus Avaritia [all, $X^{2}=0.86, \mathrm{df}=1, P=0.35$; unpigmented, $X^{2}=0.80$, $\mathrm{df}=1, P=0.37$; unpigmented, $\left.\chi^{2}=3.01, \mathrm{df}=1, P=0.08\right]$ ).

The season and geographical location of Culicoides collection influenced the temperature at which Culicoides activity began and the levels of activity reached at each temperature (Fig. 3, Additional file 5: Table S3). Populations collected from North East England (NES cohort), which primarily comprised C. impunctatus, had a cold temperature threshold for activity, as measured by the minimum temperature at which $>5 \%$ of the Culicoides population is active, of $14{ }^{\circ} \mathrm{C}$ (Fig. 3), whereas the two collections made in South East England (SES and SEA cohorts), which were dominated by Culicoides of the Avaritia subgenus, had substantially higher activity rates at all temperatures compared to Culicoides collected in the NES cohort (Fig. 3). Yet, the cold temperature threshold for activity was lower for adult Culicoides in the SEA cohort $\left(4^{\circ} \mathrm{C}\right)$ compared with those collected in the SES cohort $\left(10{ }^{\circ} \mathrm{C}\right)$, though the two populations demonstrated similar activity levels at $14{ }^{\circ} \mathrm{C}$ (Fig. 3). This pattern was similar for both the unpigmented and pigmented females in these cohorts (Fig. 3). Indeed, there were no significant (likelihood ratio test, $X^{2}=0.19, \mathrm{df}=1, P=0.66$ ) differences in flight activity between unpigmented and pigmented females of the Avaritia subgenus for both the SES and SEA cohorts. In all temperature trials, Culicoides from the same populations maintained at $20 \pm 1{ }^{\circ} \mathrm{C}$ within control pots were active, with average activity levels in control pots of $86 \%$ and $78 \%$ for the SES and SEA cohorts, respectively, indicating that any reduction in activity is a result of the colder temperatures in temperature trial pots.

A single collection was subsequently made at a site in the Scottish Borders in the summer (SBS) which consisted of a greater proportion of livestock-associated species of Culicoides compared with collections made in the NES cohort, collected less than $8 \mathrm{~km}$ away; a total of 210 of the 585 individuals tested from the SBS cohort were classified in the subgenus Avaritia whereas only 16 of the 6643 individuals tested from the NES cohort were classified in the subgenus Avaritia.

Adult Culicoides collected in the SBS cohort had a significantly greater flight activity at $12{ }^{\circ} \mathrm{C}$, the only temperature tested, compared with Culicoides collected nearby in the NES cohort, when measuring total Culicoides and pigmented females (Tukey post hoc comparisons: total, $Z=6.09, P<0.001$; pigmented females: $Z=4.84, P<0.001)$. Flight activity for $C$. impunctatus specifically at $12{ }^{\circ} \mathrm{C}$, however, was not significantly different between the NES and SBS cohorts (Tukey post hoc comparison, $Z=6.09, P=0.34$ ). Flight activity at $12{ }^{\circ} \mathrm{C}$ was not significantly different between the SES cohort and the SBS cohort for total Culicoides (Tukey post hoc comparison, $Z=0.08, P=0.99$ ), total unpigmented females (Tukey post hoc comparison, $Z=0.79$, $P=0.43$ ) and total pigmented females (Tukey post hoc comparison, $Z=-0.76, P=0.73$ ) (Fig. 4, Additional file 6: Table S4). For adults belonging to the subgenus Avaritia specifically, flight activity at $12{ }^{\circ} \mathrm{C}$ was higher for the SBS cohort compared with the SES cohort, for pigmented females only (Tukey post hoc comparison, 


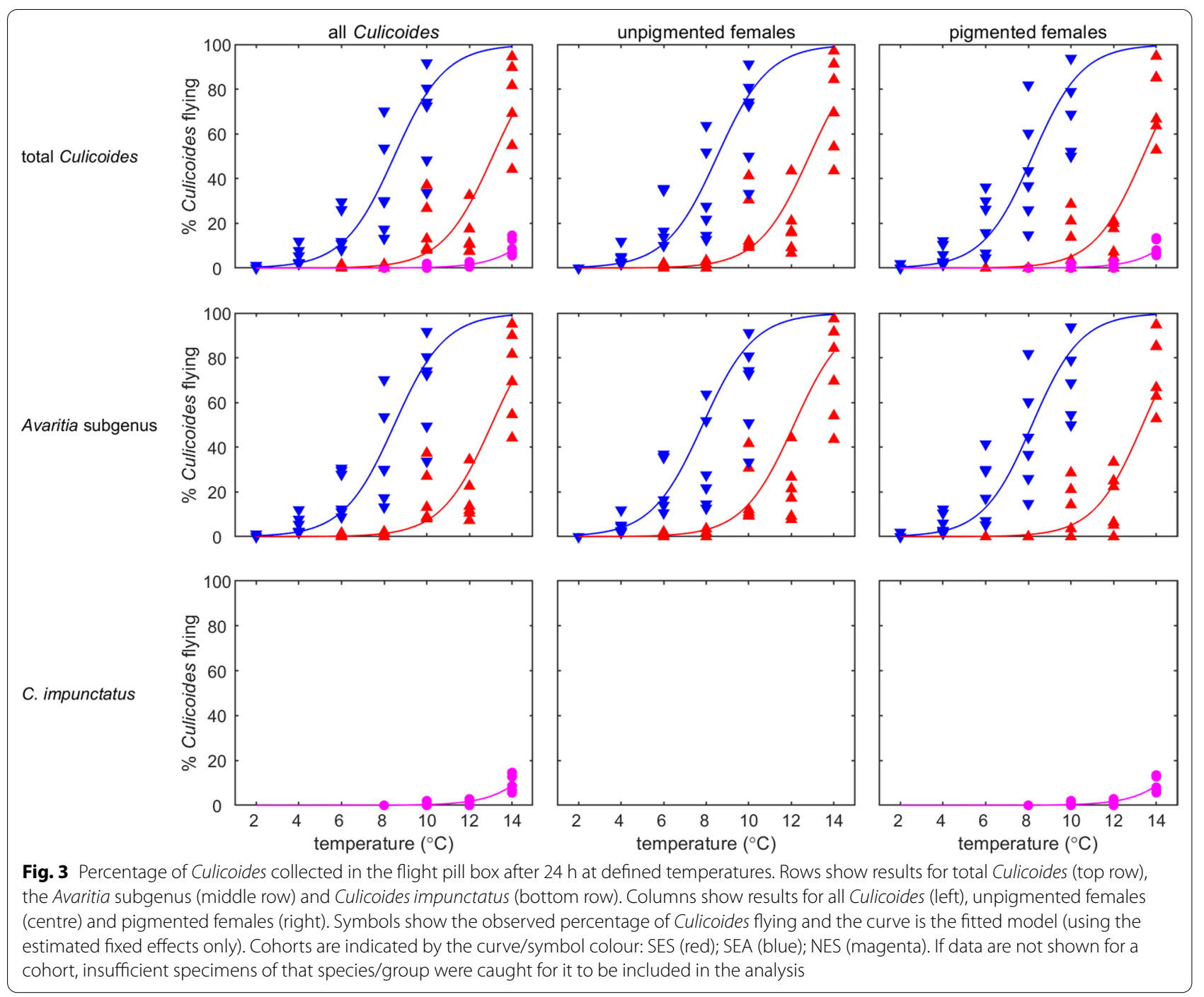

$Z=2.71, P=0.007)$. For all other physiological states within the subgenus Avaritia, activity levels between the SES and SBS cohorts were not significantly different (Tukey post hoc comparisons: total, $Z=0.82, P=0.42$; unpigmented, $Z=0.19, P=0.85$ ).

Within the South East of England, the two cryptic species within the subgenus Avaritia, $C$. obsoletus and $C$. scoticus differed in their flight activity (likelihood ratio tests: total, $X^{2}=4.71, \mathrm{df}=1, P=0.03$; unpigmented, $X^{2}=5.47, \mathrm{df}=1, P=0.02$; unpigmented, $X^{2}=5.54, \mathrm{df}=1$, $P=0.02$ ), with a greater proportion of $C$. scoticus than C. obsoletus active at all temperatures (Fig. 5, Additional file 7: Table S5). As seen in the previous analyses, adults of each species from the SEA cohort were more active at lower temperatures than those from the SES cohort (Fig. 5). Additionally, there was a greater number of individuals from the subgenus Avaritia subsample identified as C. scoticus later in the season in the SEA cohort (84\%) when compared to collections made earlier in the season in the SES cohort (37\%).

\section{Discussion}

This study has identified significant differences in temperature thresholds for flight activity of adult Culicoides according to species and season under laboratory conditions. In the populations examined in South East England, which were dominated by Culicoides of the subgenus Avaritia, the cold temperature activity threshold was higher for populations tested earlier in the season (SES: $10{ }^{\circ} \mathrm{C}$ ) compared to those collected later in the season (SEA: $4{ }^{\circ} \mathrm{C}$ ), despite similar activity rates being recorded at higher temperatures. In addition, species-specific differences in activity were recorded at an interspecific level with greater activity being recorded across the temperatures tested for $C$. scoticus relative 
to $C$. obsoletus. In addition, C. impunctatus collected in North East England (NES: $14{ }^{\circ} \mathrm{C}$ ) demonstrated significantly reduced activity across all temperatures despite an identical process of acclimatisation and test of flight fitness prior to use in the bioassay.

Studies carried out in South East England utilised two separate populations taken from summer (June-August) and autumn (September-October). The number of generations occurring each year in Culicoides in Northern Europe remains unclear, although bi- or trivoltinism has been suggested in populations of C. impunctatus [32] and the subgenus Avaritia [33]. This study highlights a significant difference in thermal tolerance of populations sampled in the same year and site using identical methods of selection, acclimatisation and measurement of activity. The underlying mechanism enabling this adaptation is unknown, although previous studies carried out in the USA demonstrated rapid cold hardening in adult $C$. sonorensis through short-term exposure to temperatures of $<5^{\circ} \mathrm{C}$ [34]. This study highlights the lack of knowledge that currently exists in the drivers of differences in behaviour, biology and ecology between generations of Culicoides.

Despite this apparent rapid adaptation to activity at cooler temperatures observed in populations in South East England, dominated by the subgenus Avaritia, testing of populations in a more northern latitude led to equivocal results. The high temperature threshold for activity in the NES cohort, of which $>99 \%$ of the total Culicoides were identified as C. impunctatus, was primarily driven by a limited flight response in populations tested within the bioassay. This was despite the fact that adults capable of flight towards light following trapping were pre-selected by the experimental design and conditions used were identical to the trials in South East England. The average flight activity response at the control temperature of $20{ }^{\circ} \mathrm{C}$ differed between cohorts; for total Culicoides collections across the SES and SEA cohorts, which were predominately comprised of Culicoides from the subgenus Avaritia, the average flight activity response at $20{ }^{\circ} \mathrm{C}$ was $86 \%$ and $78 \%$, respectively. In contrast, a greatly reduced flight activity level of $20 \%$ was observed for total Culicoides collected in the NES cohort maintained at $20{ }^{\circ} \mathrm{C}$, although this cohort was mainly comprised of C. impunctatus. Culicoides collected nearby in the SBS cohort had a greater species diversity and an increased flight activity at $20{ }^{\circ} \mathrm{C}$ of $29 \%$ suggesting that this was a species-specific response rather than a broader effect of sampling location. The reasons for the reduced response remain unclear but could represent a reduced phototactic response in particular species such as $C$. impunctatus.

The temperature thresholds for flight in populations dominated by the subgenus Avaritia populations in this study $\left(4{ }^{\circ} \mathrm{C}\right.$ in SEA and $10{ }^{\circ} \mathrm{C}$ in SES) were similar or slightly above those recorded for the temperate

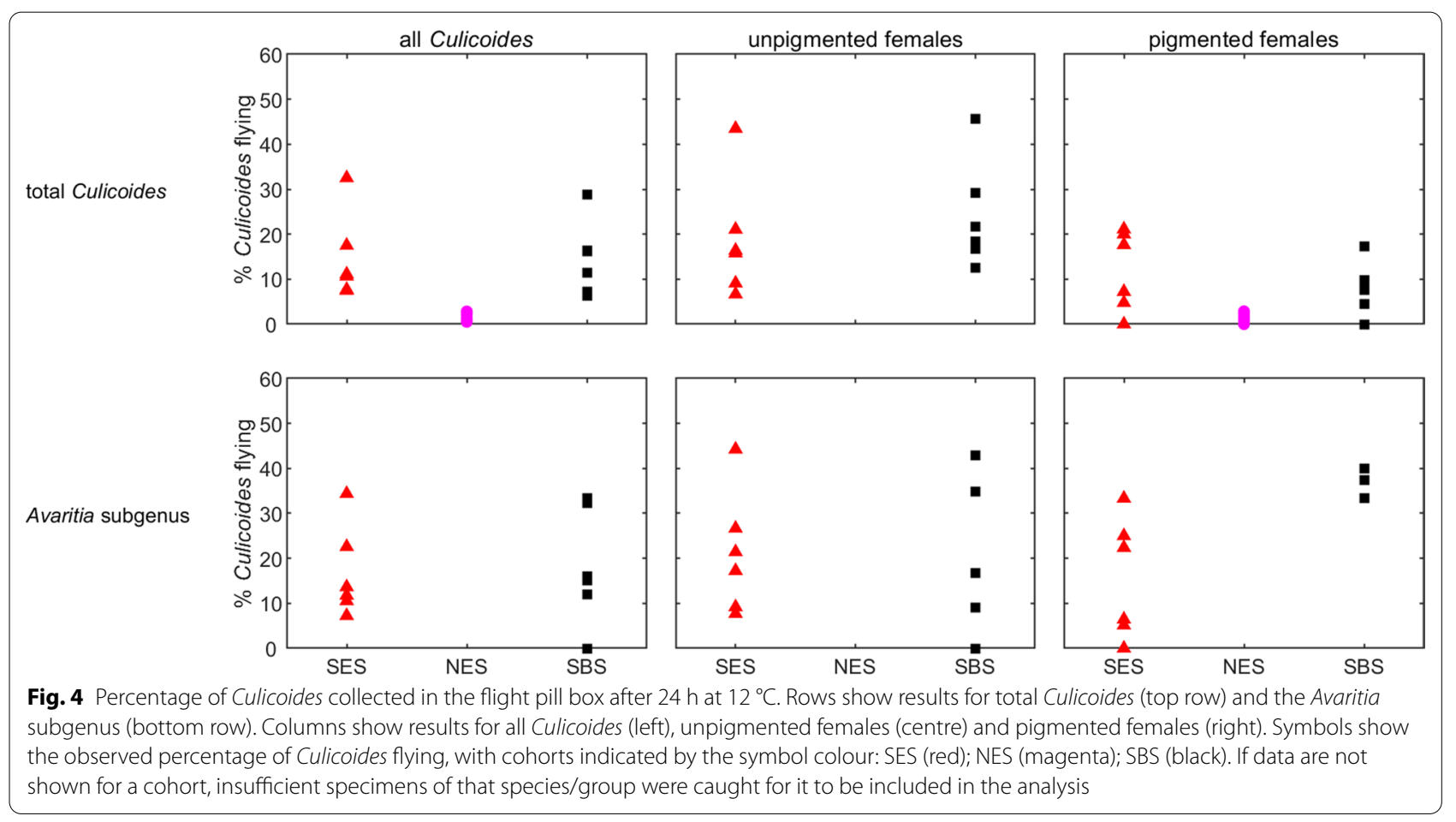



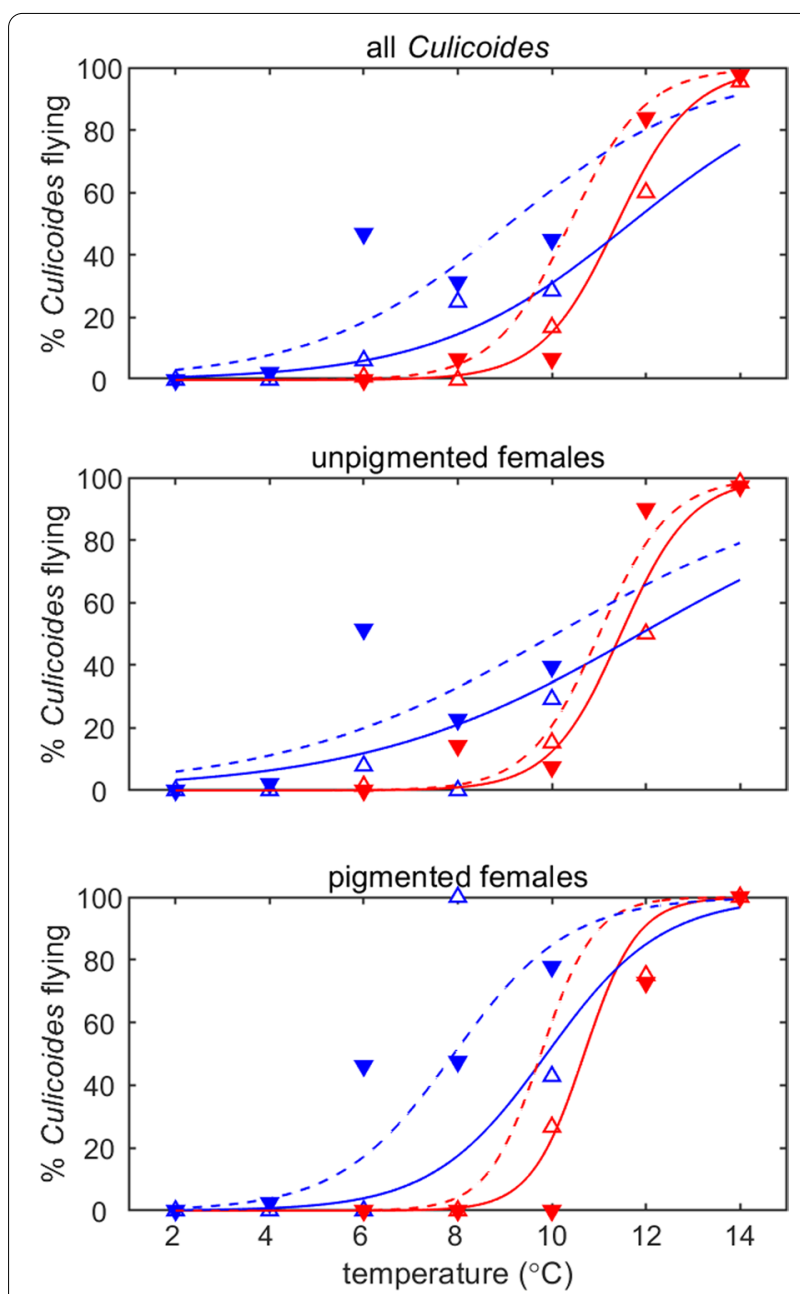

Fig. 5 Percentage of Culicoides obsoletus and Culicoides scoticus collected in the flight pill box after $24 \mathrm{~h}$. Flight activity is shown for total Culicoides (top row), unpigmented females (middle row) and pigmented females (bottom row). Symbols show the observed percentage of midges flying and the curve is the fitted model for C. obsoletus (open triangles and solid lines) and C. scoticus (filled triangles and dashed lines). Cohorts are indicated by the curve/ symbol colour: SES (red) and SEA (blue)

C. oxystoma in Japan $\left(6^{\circ} \mathrm{C}\right)$ [16], but were lower than the afrotropical C. imicola $\left(14{ }^{\circ} \mathrm{C}\right)$ in RSA [15]. One major difference in experimental design between the current study and these was the avoidance of a sorting step that necessitated cold anaesthesia prior to testing activity. This was viewed as preferable to pre-exposing the Culicoides to cold, given previous evidence of cold hardening [34]. The experimental trade-off for avoiding this step was a lack of harmonisation of density in pots due to the difficulties of estimating numbers of Culicoides introduced. While this could have led to variation in density-dependent disturbance between flight activity pots, this was not evident in the study and would have been minimal in cooler temperatures where flight was restricted to a small proportion of the midges introduced. In addition, the requirement for vertical flight, rather than horizontal, enabled a more straightforward measure of activity, potentially reducing this factor.

In terms of wider policy implications of the study, the European Food Safety Authority (EFSA) has reported previously that, based on light-suction trapping the threshold temperature required to initiate $C$. obsoletus complex adult activity was $10^{\circ} \mathrm{C}$, with temperatures of $\leq 4{ }^{\circ} \mathrm{C}$ for longer than 10 days leading to an end to adult activity [35], although differentiation between survival and activity in this report is not well defined. The disparity between predictions of activity made from lightsuction trapping and direct examination of flight could result from both the limits of using laboratory studies to define a response used in a field setting, and also the limits associated with trap surveillance. Light-suction traps are usually set at $1.5-2 \mathrm{~m}$ from ground level and have a limited effective range [26] and the period where the temperature range most often limits adult flight occurs during late autumn, winter and early spring, when risk of arbovirus incursion, and hence systematic trapping, is limited.

Vector surveillance programs, when limited, can underestimate the vector activity. The use of temperature-related baseline parameters to predict Culicoides activity, however, may provide an important tool when determining the optimal times to deploy surveillance trapping. This would provide a better assessment of transmission risk, particularly in the event of an incursion of an arbovirus. Surveillance programs using UV light suction traps can also actively select for host-seeking female Culicoides because of their increased attractiveness to light, therefore underestimating the number of Culicoides from the total population [36, 37] and also underestimating the levels of activity particularly of non-host seeking Culicoides. This study confirmed that there was no significant difference in the flight response towards a UV light stimulus between unpigmented and pigmented females of the subgenus Avaritia collected in either the summer or autumn from the same geographical location in the South East of England. This conclusion has implications when determining the SVFP, which is defined as $<5$ parous (pigmented) Culicoides specifically caught in a UV light-suction trap collection over one night, despite both unpigmented and pigmented females being equally as active and both host seeking. 
Whilst both collections from South East England consisted predominately of individuals belonging to the subgenus Avaritia, there was a far greater abundance of $C$. scoticus present in the SEA cohort (84\%) compared with the SES cohort (37\%). In this study we show, for the first time, that $C$. scoticus are significantly more active, under these laboratory conditions, at any temperature compared with C. obsoletus in both the summer and autumn, although this increased activity of C. scoticus could also have been influenced by differences in the species attractiveness to light. Due to difficulties separating these two species by morphological methods [38], differences in their behaviour as well as their vector competence have not yet been fully explored. Nevertheless, the differences in phototactic activity and seasonality between C. obsoletus and C. scoticus observed in this study could have implications for disease management, especially when determining the transmission season which could vary between species.

The flight activity of Culicoides adults can be influenced by several factors, but this present study has been limited to only temperature. Other environmental factors such as humidity, wind and rainfall have all been shown to be influential parameters in the flight response of Culicoides adults in the field [15, 39, 40]. Host-attraction cues may also play a role in the flight response of adult Culicoides populations. Consequently, measuring flight activity in response to temperature alone limits the ability to accurately define the multi-factorial flight response that would occur in the field. Furthermore, this study measured flight activity over a period of $24 \mathrm{~h}$ only, and so it is not known whether active individuals can remain active for $>24 \mathrm{~h}$, particularly at low temperatures. Further investigations into the effect of prolonged exposure to cold temperatures on adult Culicoides activity are required to assess the effect of cold temperatures at the population level in northern Europe.

\section{Conclusions}

The data presented here define cold temperature thresholds for flight activity in a range of UK Culicoides species and populations. Variation was observed in the subgenus Avaritia populations tested at different times of the year suggesting an effect of season on the activity of adult Culicoides whereby populations emerging later in the season possess a greater degree of cold tolerance. Further investigations are required to determine the effect of prolonged exposure to cold temperatures on Culicoides activity and survival to fully understand the consequence of cold winter temperatures on UK Culicoides populations and their ability to act as vectors of arboviruses.

\section{Supplementary information}

The online version contains supplementary material available at https://doi. org/10.1186/s13071-020-04552-x.

Additional file 1: Table S1. Geographic and temporal differences between Culicoides cohorts used in the study.

Additional file 2: Figure S1. CDC miniature UV light-suction trap to collect live insects in the flight activity study.

Additional file 3: Figure S2. Methods used to collect and sort Culicoides collections for the flight activity study.

Additional file 4: Table S2. Differences observed in Culicoides populations used in each temperature trial across all cohorts tested.

Additional file 5: Table S3. Estimated coefficients (standard errors) in binomial family GLMMs for flight activity (proportion of midges flying) of Culicoides biting midges.

Additional file 6: Table S4. Estimated coefficients (standard errors) in binomial family GLMMs for flight activity (proportion of midges flying) of Culicoides biting midges at $12^{\circ} \mathrm{C}$.

Additional file 7: Table S5. Estimated coefficients (standard errors) in binomial family GLMs for flight activity (proportion of midges flying) of Culicoides obsoletus and Culicoides scoticus.

\section{Abbreviations}

AHSV: African horse sickness virus; BTV: Bluetongue virus; CDC: Centers for Disease Control; EFSA: European Food Safety Authority; EIP: Extrinsic incubation period; GLMM: Generalised linear mixed model; GLM: Generalised linear model; IBH: Insect bite hypersensitivity; ITS: Internal transcribed spacer; NES: North East England summer cohort; PCR: Polymerase chain reaction; SBS: Scottish Borders summer cohort; SBV: Schmallenberg virus; SEA: South East England autumn cohort; SES: South East England summer cohort; SVFP: Seasonal vector-free period; UDG: Uracil-DNA-glycosylases; UV: Ultra-violet.

\section{Acknowledgements}

The authors thank the owners of the field sites involved in the study for their support, particularly to Kielder Campsite and Forestry Commission England for providing essential resources required for fieldwork in North East England and the Scottish Borders. We also thank Dr Emma Howson (The Pirbright Institute) for assisting with the optimisation of molecular identification of Culicoides methodology

\section{Authors' contributions}

LT performed studies, wrote and approved the submission. ME was a major contributor in writing and revising the submission and provided taxonomic expertise. SGu carried out statistical analyses and edited and approved submission. CS, JStok and JSton contributed to data acquisition. SC, KD, SGr and AB supervised the study and edited and approved the submission. LT, SC and CS contributed to development of experimental design. All authors read and approved the final manuscript.

\section{Funding}

LT is funded by a Biotechnology and Biological Sciences Research Council CASE studentship grant BB/M016196/1. ME and SC are funded by the Defra national Culicoides laboratory. SC, SGu, CS, JStok, JSton, KD and SGr are funded through strategic grants BBS/E/I/00007036 and BBS/E/I/00007038 awarded by the BBSRC. 


\section{Availability of data and materials}

All data generated or analysed during this study are included in this published article and its additional files.

\section{Ethics approval and consent to participate}

Not applicable. No technique used during the trial required ethical approval.

\section{Consent for publication}

Not applicable.

\section{Competing interests}

The authors declare that they have no competing interests.

\section{Author details}

${ }^{1}$ The Pirbright Institute, Ash Road, Woking GU24 ONF, UK. ${ }^{2}$ School of Veterinary Medicine, University of Surrey, Daphne Jackson Rd, Guildford GU2 7AL, UK. ${ }^{3}$ APS Biocontrol Ltd, Prospect Business Centre, Dundee DD2 1TY, UK.

Received: 12 October 2020 Accepted: 13 December 2020

Published online: 18 January 2021

\section{References}

1. Purse BV, Carpenter S, Venter GJ, Bellis G, Mullens BA. Bionomics of temperate and tropical Culicoides midges: knowledge gaps and consequences for transmission of Culicoides-borne viruses. Annu Rev Entomol. 2015;60:373-92

2. Carpenter S, Mellor PS, Fall AG, Garros C, Venter GJ. African horse sickness virus: history, transmission, and current status. Annu Rev Entomol. 2017:62:343-58

3. Carpenter S, Groschup MH, Garros C, Felippe-Bauer ML, Purse BV. Culicoides biting midges, arboviruses and public health in Europe. Antivir Res. 2013;100(1):102-13.

4. Sakkas H, Bozidis P, Franks A, Papadopoulou C. Oropouche fever: a review. Viruses. 2018;10(4):175.

5. Carpenter S, Wilson A, Mellor PS. Culicoides and the emergence of bluetongue virus in northern Europe. Trends Microbiol. 2009;17(4):172-8.

6. Stokes JE, Tarlinton RE, Lovatt F, Baylis M, Carson A, Duncan JS. Survey to determine the farm-level impact of Schmallenberg virus during the 2016 2017 United Kingdom lambing season. Vet Rec. 2018;183(22):690.

7. Koenraadt CJM, Balenghien T, Carpenter S, Ducheyne E, Elbers ARW, Fife $\mathrm{M}$, et al. Bluetongue, Schmallenberg - what is next? Culicoides-borne viral diseases in the 21st Century. BMC Vet Res. 2014;10:77.

8. Balenghien T, Pagès N, Goffredo M, Carpenter S, Augot D, Jacquier E, et al. The emergence of Schmallenberg virus across Culicoides communities and ecosystems in Europe. Prev Vet Med. 2014;116(4):360-9.

9. King S, Rajko-Nenow P, Ashby M, Frost L, Carpenter S, Batten C. Outbreak of African horse sickness in Thailand, 2020. Transbound Emerg Dis. 2020:67:1764-1176.

10. Wittmann EJ, Baylis M. Climate change: effects on Culicoides-transmitted viruses and implications for the UK. Vet J. 2000;160(2):107-17.

11. Carpenter S, Wilson A, Barber J, Veronesi E, Mellor P, Venter G, et al. Temperature dependence of the extrinsic incubation period of Orbiviruses in Culicoides biting midges. PLoS ONE. 2011;6(11):e27987.

12. Wilson A, Darpel K, Mellor PS. Where does bluetongue virus sleep in the winter? PLoS Biol. 2008;6:8.

13. Mayo C, Mullens B, Gibbs EP, MacLachlan NJ. Overwintering of bluetongue virus in temperate zones. Vet Ital. 2016;52:243-6.

14. Wellby MP, Baylis M, Rawlings P, Mellor PS. Effect of temperature on survival and rate of virogenesis of African horse sickness virus in Culicoides variipennis sonorensis (Diptera: Ceratopogonidae) and its significance in relation to the epidemiology of the disease. Bull Entomol Res. 1996;86(6):715-20.

15. Venter GJ, Boikanyo SNB, de Beer CJ. The influence of temperature and humidity on the flight activity of Culicoides imicola both under laboratory and field conditions. Parasit Vectors. 2019;12:4.

16. Tsutsui T, Hayama Y, Yamakawa M, Shirafuji H, Yanase T. Flight behavior of adult Culicoides oxystoma and Culicoides maculatus under different temperatures in the laboratory. Parasitol Res. 2011;108(6):1575-8.
17. Carpenter S, Szmaragd C, Barber J, Labuschagne K, Gubbins S, Mellor P. An assessment of Culicoides surveillance techniques in northern Europe: have we underestimated a potential bluetongue virus vector? J Appl Ecol. 2008;45(4):1237-45.

18. Sanders CJ, Gubbins S, Mellor PS, Barber J, Golding N, Harrup LE, et al. Investigation of diel activity of Culicoides biting midges (Diptera: Ceratopogonidae) in the United Kingdom by using a vehicle-mounted trap. J Med Entomol. 2012;49(3):757-65.

19. Cuéllar AC, Jung Kiær L, Baum A, Stockmarr A, Skovgard H, Nielsen SA et al. Monthly variation in the probability of presence of adult Culicoides populations in nine European countries and the implications for targeted surveillance. Parasit Vectors. 2018;11:608

20. Cuéllar AC, Jung Kjær L, Baum A, Stockmarr A, Skovgard H, Nielsen SA, et al. Modelling the monthly abundance of Culicoides biting midges in nine European countries using Random Forests machine learning. Parasit Vectors. 2020;13:194.

21. Cuéllar AC, Jung Kjær L, Kirkeby C, Skovgard H, Nielsen SA, Stockmarr A, et al. Spatial and temporal variation in the abundance of Culicoides biting midges (Diptera: Ceratopogonidae) in nine European countries. Parasit Vectors. 2018;11:112.

22. Baldet T, Delecolle JC, Cetre-Sossah C, Mathieu B, Meiswinkel R, Gerbier G. Indoor activity of Culicoides associated with livestock in the bluetongue virus (BTV) affected region of Northern France during autumn 2006. Prev Vet Med. 2008;87:84-97.

23. Kameke D, Kampen H, Walther D. Activity of Culicoides spp. (Diptera: Ceratopogonidae) inside and outside of livestock stables in late winter and spring. Parasitol Res. 2017:116(3):881-889.

24. Stokes J:The epidemiology and surveillance of Culicoides-borne diseases of ruminants in the UK. University of Liverpool; 2017.

25. Searle KR, Barber J, Stubbins F, Labuschagne K, Carpenter S, Butler A, et al. Environmental drivers of Culicoides phenology: how important is species-specific variation when determining disease policy? PLoS ONE. 2014;9(11):e111876.

26. Kirkeby C, GræsbøII, K., Stockmarr, A., Christiansen, L,E., Bødker, R. The range of attraction for light traps catching Culicoides biting midges (Diptera: Ceratopogonidae). Parasit Vectors. 2013;6:67.

27. Campbell JA, Pelham-Clinton EC. A taxonomic review of the British species of Culicoides Latreille (Diptera, Ceratopogonidae). Proc R Soc Edinburgh. 1960;67:181-302.

28. Dyce AL. The recognition of nulliparous and parous Culicoides (Diptera: Ceratopogonidae) without dissection. J Aust Entomol Soc. 1969;8:11-5.

29. Mathieu B, Delecolle JC, Garros C, Balenghien T, Setier-Rio ML, Candolfi $E$, et al. Simultaneous quantification of the relative abundance of species complex members: application to Culicoides obsoletus and Culicoides scoticus (Diptera: Ceratopogonidae), potential vectors of bluetongue virus. Vet Parasitol. 2012;190:619.

30. Bates D, Machler M, Bolker BM, Walker SC. Fitting Linear Mixed-Effects Models Using Ime4. J Stat Softw. 2015;67:1-48

31. Team RC. R: A Language and Environment for Statistical Computing. Vienna: R Foundation for Statistical Computing; 2019.

32. Blackwell A, Mordue AJ, Young MR, Mordue W. Bivoltinism, survival rates and reproductive Characteristics of the Scottish biting midge, Culicoides Impunctatus (Diptera, Ceratopogonidae) in Scotland. B Entomol Res. 1992;82(3):299-306

33. Birley MH, Boorman JPT. Estimating the survival and biting rates of hematophagous insects, with particular reference to the Culicoides obsoletus group (Diptera, Ceratopogonidae) in Southern England. J Anim Ecol. 1982;51:135-48.

34. Nunamaker RA. Rapid cold-hardening in Culicoides Variipennis Sonorensis (Diptera, Ceratopogonidae). J Med Entomol. 1993;30(5):913-7.

35. Versteirt $\mathrm{V}$, Balenghien T, Tack W, Wint W. A first estimation of Culicoides imicola and Culicoides obsoletus/Culicoides scoticus seasonality and abundance in Europe. EFSA Support Publ. 2017;14.

36. Venter GJ, Labuschagne K, Hermanides KG, Boikanyo SNB, Majatladi DM, Morey L. Comparison of the efficiency of five suction light traps under field conditions in South Africa for the collection of Culicoides species. Vet Parasitol. 2009;166:299-307.

37. McDermott EG, Mayo CE, Gerry AC, Mullens BA. Trap placement and attractant choice affect capture and create sex and parity biases in collections of the biting midge. Culicoides sonorensis. Med Vet Entomol. 2016:30(3):293-300 
38. Kluiters G, Pages N, Carpenter S, Gardes L, Guis H, Baylis M, et al. Morphometric discrimination of two sympatric sibling species in the Palaearctic region, Culicoides obsoletus Meigen and C. scoticus Downes \& Kettle (Diptera: Ceratopogonidae), vectors of bluetongue and Schmallenberg viruses. Parasit Vectors. 2016;9:262

39. Blackwell A. Diel flight periodicity of the biting midge Culicoides impunctatus and the effects of meteorological conditions. Med Vet Entomol. 1997;11(4):361-7.
40. Sanders CJ, Shortall CR, Gubbins S, Burgin L, Gloster J, Harrington R, et al. Influence of season and meteorological parameters on flight activity of Culicoides biting midges. J Appl Ecol. 2011;48(6):1355-64.

\section{Publisher's Note}

Springer Nature remains neutral with regard to jurisdictional claims in published maps and institutional affiliations.
Ready to submit your research? Choose BMC and benefit from:

- fast, convenient online submission

- thorough peer review by experienced researchers in your field

- rapid publication on acceptance

- support for research data, including large and complex data types

- gold Open Access which fosters wider collaboration and increased citations

- maximum visibility for your research: over $100 \mathrm{M}$ website views per year

At BMC, research is always in progress.

Learn more biomedcentral.com/submissions 